low birthweight in his 1978 review. Miller et al (1987) have reported that low birthweight is associated with a large number and variety of risk conditions, often acting multiplicatively, which include cigarette smoking, lack of prenatal care, physique of mother, teenage pregnancy, behavioural and environmental risks, health care risks, drug addiction and chronic alcoholism. We found that some of these were raised in the mothers of schizophrenics and in addition those not documented in the 1958 study (such as drug addiction and alcoholism) are known to be found more often in first degree relatives (i.e. parents). Thus if birthweight does turn out to be lower in people with schizophrenia it may well be due to multiple risk arising from the physique and lifestyle of the mother.

Rifkin \& Takei's final point missed the analysis reported on p. 787. A logistic regression, with schizophrenia of cohort member as the dependent variable, was calculated with any parental psychological disorder fitted first before fitting the physique/lifestyle variables identified earlier. Even when parental psychological disorder (which included schizophrenia in parents) was removed the increased risk in the parents of schizophrenics remained on a number of measures.

We would agree with Mortensen et al that a debate is long overdue on alternatives to the theory that minor OCs cause a neurodevelopmental disorder later presenting as schizophrenia. The voluminous literature suggests that Lilienfeld $e t a l$ s 1950s concept of "a continuum of reproductive causality" has not stood the test of time, but this has been overlooked. For example psychological sequelae of pregnancy/perinatal damage are widely reported to be modulated by social and familial environment. Good environments foster and poor environments fail to provide the potential for recovery. Since early socio/environmental disadvantage does not increase the risk of schizophrenia, this diathesis is unlikely to be found. Alternative explanations for the association between OCs and schizophrenia will then be required

EMSLIE, et al (1993) Do clinical guidelines improve general practice management and referral of infertile couples. British Medical Journal, 306, 1728-1731.

MCNeIL, T. F. (1987) Perinatal influences in the development of schizophrenia. In: Biological Perspectives of Schizophrenia (eds H. Helmchen \& F. A. Henn) Chichester: John Wiley.

O'Callaghan, E., et al (1990) Obstetric complications in schizophrenia and the validity of maternal recall. Psychological Medicine, 20, 89-94.

MiLleR, H. C., et al (1987) Incidence of low birth weight infants born to mothers with multiple risk factors. Yale Journal of Biology and Medicine, 60, 397-404.
D. J. DONE

A. SACKER

University of Hertfordshire

Hatfield, Herts AL10 9AB

Eugenics

SIR: The editorial by Pearson (1995) concludes with the warning that opposition to the Chinese eugenicist birth policy law will be more effective if it eschews the "high moral ground", and focuses rather on the fact that such a policy is unscientific. This caveat, if indeed honoured by 'Westerners', may or may not prove to be prescient; but, either way, it is an unwise path to follow.

Policies of eugenics are bound inextricably to salient issues of morality. To pretend otherwise, or to focus on its unscientific nature to the exclusion of pressing moral concerns, constitutes an unconscionable, and improper, breach of academic candor and forthrightness. Although Pearson (1995) comments that moral arguments against eugenics may stir up, in the minds of Chinese, a spectre of cultural imperialism, it is hard to fathom how this may come about if the morality of eugenics is debated in an intellectual environment permeated by even a modicum of free expression of thought. To deliberately fail to stress, or even mention, that, historically, eugenics policies have been fettered by indissoluble bonds to pressing moral concerns appears to constitute, ultimately, a foolish, misguided attempt to grovel at the feet of those ignorant of historic truths, or else bent intentionally on doing wrong. Historically, attempts to appease those suffering from these latter ailments have failed; and they will likely fail afresh, if attempted now.

The correct path to follow is to emphasise that eugenics policies, historically, have thrived in the soil of authoritarianism and dictatorship. And that the present Chinese eugenicist policies are scions of historical roots which thrived during the barbarism of Hitler's Third Reich. Indeed, for many, the term eugenics will immediately conjure up images of Nazi Germany and widescale euthanasia. Any honest discussion of eugenics should mention also that the burgeoning number of gene tests under furious development have tentacles reaching potentially to eugenics policies, as well as policies of genetic-related discrimination extending to insurance and employment (Uzych, 1986, 1992, 1995).

China, in sum, is sliding rapidly down a path towards moral degradation; and this disturbing development should not be ignored. 
Pearson. V. (1995) Population poplicy and eugenics in China. British Journal of Psychiatry, 167, 1-4.

UzYCH, L. (1986) Genetic testing and exclusionary practices in the workplace. Journal of Public Health Policy, 7, 37-57.

- (1992) Human genetics, bioethics, and the law. Journal of the National Cancer Institute, 84, 127-128.

- (1995) Genetic testing for children and adolescents. Journal of the American Medical Association, 273, 1089-1090.

103 Canterbury Drive

L. UZYCH

Wallingford, PA 19086, USA

\section{Mania precipitated by carbamazepine withdrawal}

SIR: The anticonvulsant carbamazepine is as effective as lithium in the prophylaxis of bipolar affective disorders (Coxhead et al, 1992) and may be considered as a possible alternative to it. There has been a debate about whether discontinuation of lithium may precipitate a rebound manic or depressive episode (Schou, 1993). Carbamazepine has not been thought to have any affective withdrawal effects. We wish to report the case of an epileptic woman in whom withdrawal of carbamazepine has twice precipitated a manic episode.

MK is a 30-year-old who has had complex partial seizures for 12 years. Neurological examination is normal. Her EEG shows bi-temporal or left frontotemporal abnormalities. CT and MRI examinations are normal.

She has taken carbamazepine for her epilepsy for 10 years. Seizures have continued despite doses up to $1000 \mathrm{mg}$ bd. Recently valproate, $2500 \mathrm{mg}$ per day, then phenytoin, $200 \mathrm{mg}$ per day, were added and carbamazepine gradually withdrawn.

Five days after stopping carbamazepine she had a single nocturnal fit. Two days later she presented complaining of insomnia, poor appetite, increased energy and racing thoughts. Elated mood alternated with brief episodes of dysphoria and suicidal ideation. She was distractible and mildly disinhibited. There was some pressure of speech. She felt 'more sensitive' than usual but did not appear hallucinated or deluded. Her EEG taken at presentation was unchanged and excluded complex partial status. Carbamazepine was restarted and the dose gradually increased to $300 \mathrm{mg}$ bd. Her mood settled over three weeks and has remained stable for several months.

Her previous psychiatric history is of a single episode of mania. This started four days after abruptly stopping carbamazepine two years earlier. It was characterised by mildly euphoric mood, a sense of cosmic importance "like being god", agitation and poor sleep. She responded to reintroduction of carbamazepine and addition of chlorpromazine.

MK's symptoms fit ICD-10 diagnostic guidelines for a manic episode. On both occasions her manic illness responded to the reintroduction of carbamazepine. We are not aware of any other reports of carbamazepine withdrawal being associated with a manic episode.

Coxhead, N. Silverstone, T. \& CoOkson, J. (1992) Carbamazepine versus lithium in the prophylaxis of bipolar affective disorder. Acta Psychiatrica Scandinavica. 85, 114-118.

Schou, M. (1993) Is there a lithium withdrawal syndrome? An examination of the evidence. British Journal of Psychiatry, 163, 514-518.

D. A. SCULL

Institute of Neurology

M. R. TRIMBLE

London WCIN $3 B G$

\section{Laryngeal dystonia}

SIR: I read with interest the letter describing neuroleptic induced dysphonia (Thorburn, 1995). Dystonia of the laryngeal muscles can be frightening and is easily missed, as the following case report illustrates.

A 14-year-old male on no medication and with no past psychiatric history was admitted following an overdose of $500 \mathrm{mg}$ chlorpromazine and $80 \mathrm{mg}$ of fluoxetine in addition to approximately 8 units of alcohol. A good result from a stomach washout was reported within four hours of the overdose. Thirtysix hours later he experienced difficulty in speaking followed rapidly by a choking sensation. This resolved spontaneously and the incident was recorded as a panic attack. The following day his intermittent problems with vocalisation were attributed to anxiety; a psychiatric assessment was hindered by his fluctuating but severe dystonia involving muscles of the head, neck and trunk. Laryngeal dystonia rendered him profoundly dysphonic. Involvement of oropharyngeal muscles resulted in a temporary but distressing maximal protrusion of the tongue with venous congestion, swelling and discomfort. Fortunately his airway was maintained, except perhaps briefly during his panic attack, and intravenous and subsequently oral procyclidine prevented further episodes.

Acute dystonia is a well recognised adverse effect of neuroleptics, and in this case fluoxetine may have exacerbated this effect. Although the possibility of acute dystonia following overdose and its appropriate management is described both in the ABPI data sheet and by the Poisons Bureau, laryngeal dystonia 